\title{
Diagnosis of ocular sarcoidosis and ACE in tears
}

To the Editor:

Dr G. Rizzato and his colleagues quite appropriately emphasize that, in any patient with unexplained and undiagnosed uveitis, the diagnosis of sarcoidosis should be considered, even if the chest radiograph is normal. When indicated, bronchoalveolar lavage, transbronchial lung biopsy, and computerized examination of the chest should be performed to exclude the multisystem nature of the disease [1]. I believe an appropriate and timely use of gallium-67 body scan will also uncover a few sites of granulomatous involvement.

Furthermore, I believe that measuring angiotensin converting enzyme (ACE) activity in serum and tears, particularly the latter, can be of help in supporting the diagnosis of ocular sarcoidosis and monitoring its response to corticosteroid therapy, especially in patients who lack evidence of multisystem involvement $[2,3]$.

\section{References}

1. Rizzato G, Angi M, Fraioli P, et al. Uveitis as a presenting feature of chronic sarcoidosis. Eur Respir J 1996; 9: 1201-1205.

2. Weinreb R, Kimura S. Uveitis associated with sarcoidosis and angiotensin-converting enzyme. Am J Ophthalmol 1980; 89: 180-185.

3. Sharma O, Vita J. Determination of angiotensin-converting enzyme activity in tears: a noninvasive test for evaluation of ocular sarcoidosis. Arch Ophthalmol 1983; 101: 559-561.

\section{O.P. Sharma}

Room 11-900, LAC + USC Medical Center, 1200 North State Street, Los Angeles, CA 90033, USA.

\section{REPLY}

\section{From the authors:}

We thank Professor Sharma for his interest in our work, and for his comments.

Our study was retrospective, from October 1978 in Milan, and from October 1980 in Padua. In the early 1980 s, our patients underwent ${ }^{67} \mathrm{Ga}$ lung scan, whilst ${ }^{67} \mathrm{Ga}$ total body scan was introduced in 1986 . For this reason, we could not show the ${ }^{67} \mathrm{Ga}$ total body scan in the work-up of our patients over so many years of follow-up, but simply the lung scan. However, we completely agree on the usefulness of ${ }^{67} \mathrm{Ga}$ total body scan in cases of uveitis of suspected sarcoid origin. This is our current policy.

By contrast, the usefulness of angiotensin-converting enzyme (ACE) activity in tears is today an open question. In 1983, SHARMA and ViTA [1] observed that the measurement of ACE levels in tears provided the best noninvasive test for diagnosing ocular sarcoidosis and monitoring the course of the disease. They studied 25 patients with sarcoidosis, but a serial measurement of ACE in tears was carried out in only two patients: in both patients, tear ACE level dropped under corticosteroid therapy. It is now known that the usefulness of ACE is limited in patients taking corticosteroids, which suppress ACE activity independently of the clinical status, not only in sarcoidosis [2] but also in normal subjects [3], as well as in asthmatic patients [4].

In 1987, IMMONEN et al. [5] observed that ACE levels in tears were elevated in sarcoidosis, but this elevation appeared to be independent of eye involvement and seemed to vary irrespective of the intraocular activity of sarcoidosis. They concluded that tear ACE level is not a specific test for ocular sarcoidosis, and that it is of limited value in the clinical evaluation of ocular sarcoidosis. Moreover, in 1981 VAn HaERINGEN [6] observed that analysis of tear samples is difficult, as dilution and origin of tear fluid vary with the amount of irritation to the eye caused by collection of the sample.

Surprisingly, no other works (to our knowledge) have appeared on this subject in the last 10 yrs. We think that more information is needed to determine whether the level of angiotensin-converting enzyme in tears can be of help in supporting the diagnosis of ocular sarcoidosis and monitoring its response to corticosteroid therapy.

\section{References}

1. Sharma O, Vita J. Determination of angiotensin-converting enzyme activity in tears. Arch Ophthalmol 1983; 101: 559-561.

2. Baughman R, Ploysongsang Y, Roberts R. Effects of sarcoid and steroids on angiotensin-converting enzyme. Am Rev Respir Dis 1983; 128: 631-633.

3. Selroos O. Value of biochemical markers in serum for determination of disease activity in sarcoidosis. Sarcoidosis 1984; 1: 45-49.

4. Roulson J, O'Malley G, Douglas J. Effects of prednisolone on angiotensin-converting enzyme activity. Thorax 1984; 39: 356-360.

5. Immonen I, Friberg K, Sorsila R, Fyhrquist F. Concentration of angiotensin-converting enzyme in tears of patients with sarcoidosis. Acta Ophthalmol 1987; 65: 27-29.

6. Van Haeringen N. Clinical biochemistry of tears. Surv Ophthalmol 1981; 26: 84-96.

\section{G. Rizzato*, M. Angi**}

*Sarcoid Clinic, Niguarda Hospital, Milan, Italy. **Institute of Ophthalmology, Padua University, Padua, Italy. 